\title{
Two Novel Variants and One Previously Reported Variant in the Insulin Receptor Gene in Two Cases with Severe Insulin Resistance Syndrome
}

\author{
Aydilek Dagdeviren Cakir ${ }^{a}$ Said Saidov ${ }^{b}$ Hande Turan $^{a}$ Serdar Ceylaner $^{c}$ \\ Yavuz Özera Tufan Kutlu ${ }^{d}$ Oya Ercan ${ }^{a}$ Olcay Evliyaoglua \\ a Department of Pediatric Endocrinology, Cerrahpasa Medical School, Istanbul University-Cerrahpasa, Istanbul,

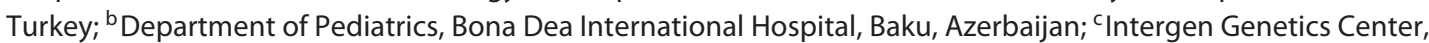 \\ Ankara, Turkey; ${ }^{\mathrm{d}}$ Department of Pediatric Gastroenterology, Cerrahpasa Medical School, Istanbul University- \\ Cerrahpasa, Istanbul, Turkey
}

\section{Established Facts}

- Biallelic pathogenic variants in the insulin receptor gene cause severe insulin resistance syndromes, Donohue (DS) and Rabson-Mendenhall syndrome (RMS).

- In the presence of dysmorphic features and hyperinsulinemia with fasting hypoglycemia and postprandial hyperglycemia, severe insulin resistance syndromes should be kept in mind.

\section{Novel Insights}

- The 2 novel homozygous variants c.3122delA (p.N1041Mfs*16) and c.3419C>G (p.A1140G) in the INSR gene lead to DS with cholestasis and enlarged multicystic ovaries.

- The c.3529+5G >A (IVS19+5G>A) variant detected in the RMS case is reported for the second time. It was previously reported in a case with similar clinical features from our country, suggesting that the variant was pathogenic.

\section{Keywords}

Acanthosis nigricans · Donohue syndrome · INSR ·

Rabson-Mendenhall syndrome

\begin{abstract}
Donohue syndrome (DS) and Rabson-Mendenhall syndrome (RMS) are rare diseases caused by biallelic variants within the insulin receptor gene (INSR). Here, we report 2 cases: one with DS and the other with RMS. The case with DS presented
\end{abstract}

with intrauterine growth retardation, nipple hypertrophy, clitoromegaly, distended abdomen, hypertrichosis, and dysmorphic features. The second case showed severe acanthosis nigricans, hyperkeratosis, and hypertrichosis. In both cases, abnormal glucose homeostasis due to severe insulin resistance was observed. The diagnosis of DS and RMS was established based on clinical characteristics, abnormal glucose homeostasis, high serum insulin levels, and determination of pathogenic variants in the INSR gene. The first case with DS has 2 novel homozygous variants, NM_000208.3,

\section{KARGER}

(c) 2020 S. Karger AG, Basel

karger@karger.com

www.karger.com/msy
Aydilek Dagdeviren Cakir

Department of Pediatric Endocrinology

Cerrahpasa Medical School, Istanbul University-Cerrahpasa

Istanbul 34098 (Turkey)

aydi.dagdeviren@hotmail.com 
c.3122delA (p.N1041Mfs*16) and c.3419C>G (p.A1140G), and the second case with RMS has a previously reported homozygous variant NM_000208.3, c.3529+5G>A (IVS19+5G>A) in the INSR gene.

(c) 2020 S. Karger AG, Basel

The insulin receptor (INSR) consists of 2 extracellular $\alpha$-subunits mediating insulin binding and 2 intracellular $\beta$-subunits with tyrosine kinase activity [Ebina et al., 1985]. Pathogenic variants in the INSR gene are responsible for a spectrum of inherited insulin-resistance syndromes. While Donohue syndrome (DS) is the most severe form, Rabson-Mendenhall syndrome (RMS) represents an intermediate form. In DS, most of the patients die in the first year of life due to diabetic complications and sepsis. It is characterized by intrauterine/postnatal growth retardation and dysmorphic features with thick lips, broad nose, bulging eyes, and large and low-set ears. Other common clinical features are reduced adipose tissue, muscular atrophy, acanthosis nigricans, hypertrichosis, distended abdomen, and enlarged external genitalia and nipples. Glucose homeostasis is affected with severe insulin resistance, fasting hypoglycemia and postprandial hyperglycemia [Donohue and Uchida, 1954; Semple et al., 2011]. Both DS and RMS are of autosomal recessive inheritance [Longo et al., 1992]. Patients with RMS are characterized by coarse facial features, growth retardation, severe acanthosis nigricans, hypertrichosis, dental and nail abnormalities as well as large external genitalia. Clinical findings are less severe than DS, and patients can live up to the second decade [Rabson and Mendenhall, 1956; Longo et al., 1999].

We report 2 cases with severe insulin resistance syndromes, one with DS and the other with RMS, repre-
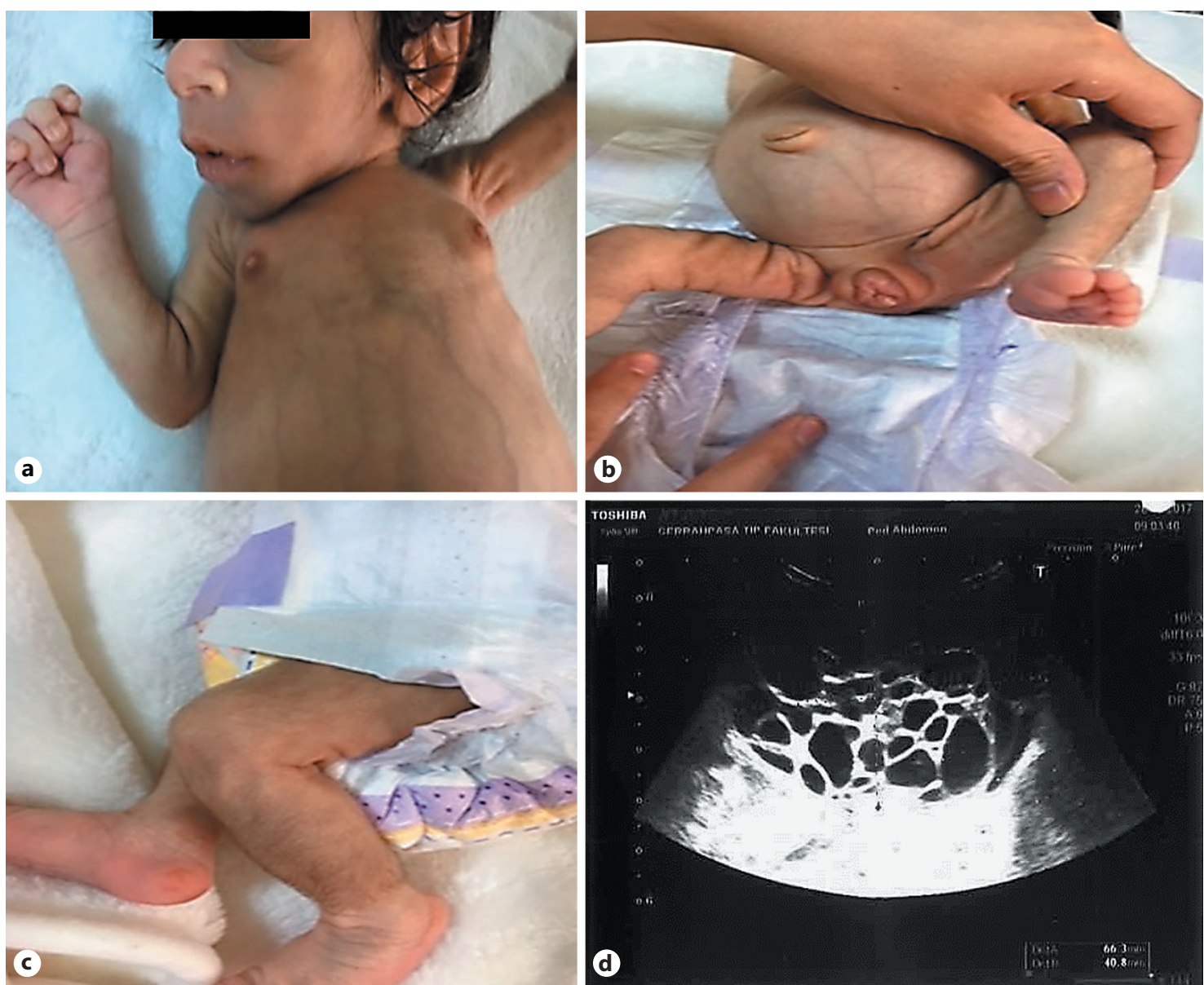

Fig. 1. a-c Characteristic dysmorphic features of Donohue syndrome: elfin face, prominent eyes, large and lowset ears, depressed nasal bridge with broad nasal tip, thick lips, breast hyperplasia, abdominal distension, cliteromegaly, hypertrichosis, and reduced subcutaneous fat. d Pelvic ultrasonography showing an enlarged right ovary with multiple cysts.

Two Novel Variants and One Previously Reported Variant in INSR
Mol Syndromol 2020;11:90-96 DOI: $10.1159 / 000506722$ 


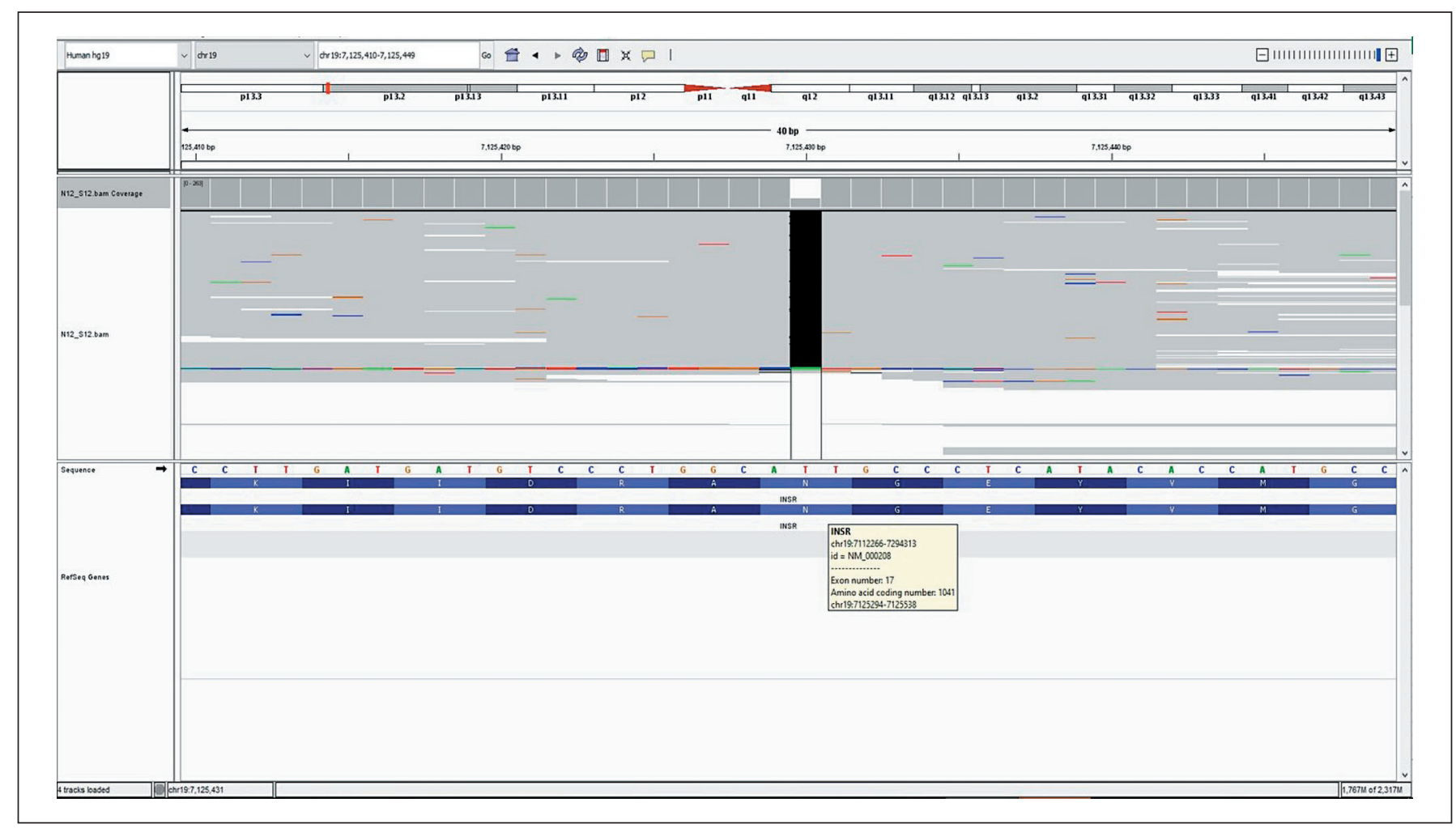

Fig. 2. Analysis of the novel homozygous variant (c.3122delA) in exon 17 in the INSR gene.

senting severe and moderate aspects of the disorder, respectively. Case 1 with DS has 2 novel homozygous variants NM_000208.3, c.3122delA (p.N1041Mfs*16) and c.3419C $>\mathrm{G}$ (p.A1140G) in the INSR gene, and case 2 with RMS has a c.3529+5G $>$ A (IVS19+5G $>$ A) variant reported for the second time.

\section{Case Presentations}

Case 1

A female neonate born at 38 week's gestation with a birth weight of $1,650 \mathrm{~g}(-4.12 \mathrm{SD})$ presented with dysmorphic features and fluctuations between hyper- and hypoglycemia. Birth length was $42 \mathrm{~cm}(-3.48 \mathrm{SD})$ and her head circumference was $32 \mathrm{~cm}$ $(-1.81 \mathrm{SD})$. Parents are second-degree cousins. Physical examination revealed: elfin face with prominent eyes, flat nasal root, anteverted nostrils, low-set and large ears as well as thick lips. Additionally, wasted appearance with decreased adipose tissue, diffuse hypertrichosis, cliteromegaly, nipple hypertrophy, and abdominal distension were present (Fig. 1a-c). Her hemogram, liver (AST: 26 $\mathrm{U} / \mathrm{L}, \mathrm{ALT}: 17 \mathrm{U} / \mathrm{L}$ ), renal function tests (urea: $5 \mathrm{mg} / \mathrm{dL}$, creatinine: $0.2 \mathrm{mg} / \mathrm{dL}$ ), and serum electrolytes were all in normal ranges. She was noted to have hyperglycemia, reaching a level of $450 \mathrm{mg} / \mathrm{dL}$, requiring insulin treatment on the postnatal 9th day. Nevertheless, neither acidosis nor ketonuria occurred. Due to development of recurrent hypoglycemias, insulin treatment was discontinued after 1 day of treatment. Concurrent insulin and c-peptide levels at the time of hypoglycemia were $>1,000 \mathrm{IU} / \mathrm{L}$ and $>40 \mathrm{ng} / \mathrm{mL}$, respectively. On the following days, episodes of postprandial hyperglycemia and preprandial hypoglycemia were observed, and glucose levels ranged between 40 and $180 \mathrm{mg} / \mathrm{dL}$. The frequency of fasting hypoglycemia was once or twice a day. The typical phenotypic appearance and the abovementioned fluctuations suggested DS, and genetic analysis revealed 2 novel homozygous variants in the INSR gene, NM_000208.3, c.3122delA and c.3419C $>$ G in exon 17 (Fig. 2) and 19 (Fig. 3), respectively. The first one was a frameshift variant that most probably led to a nonsense-mediated mRNA decay or to a nonfunctioning insulin receptor, explaining the severe clinical picture of DS. Functional consequence of the second variant was evaluated by in silico analysis programs (Varsome, MutationTaster, PolyPhen-2, Provean, and SIFT) and found to be highly damaging. As this is a null variant, it is most probably a diseasecausing variant. Both parents were found to be heterozygous for the same variants. Genetic counseling was provided to the parents.

The patient was discharged with recommendation of frequent feeding. At 10 weeks of age, she was rehospitalized due to aspiration pneumonia. She had feeding difficulty due to abdominal distension. Thus, continuous enteral feeding which also decreased the frequency of hypoglycemic episodes was started. At this visit, direct hyperbilirubinemia with a cholestatic picture (total bilirubin: $5.2 \mathrm{mg} / \mathrm{dL}$, direct bilirubin: $3.1 \mathrm{mg} / \mathrm{dL}$, AST:136 IU/L, ALT:47 IU/L, GGT: 254 IU/L, and ALP: 312 IU/L) was also determined, and ursodeoxycolic acid was started. Abdominal ultrasound re- 


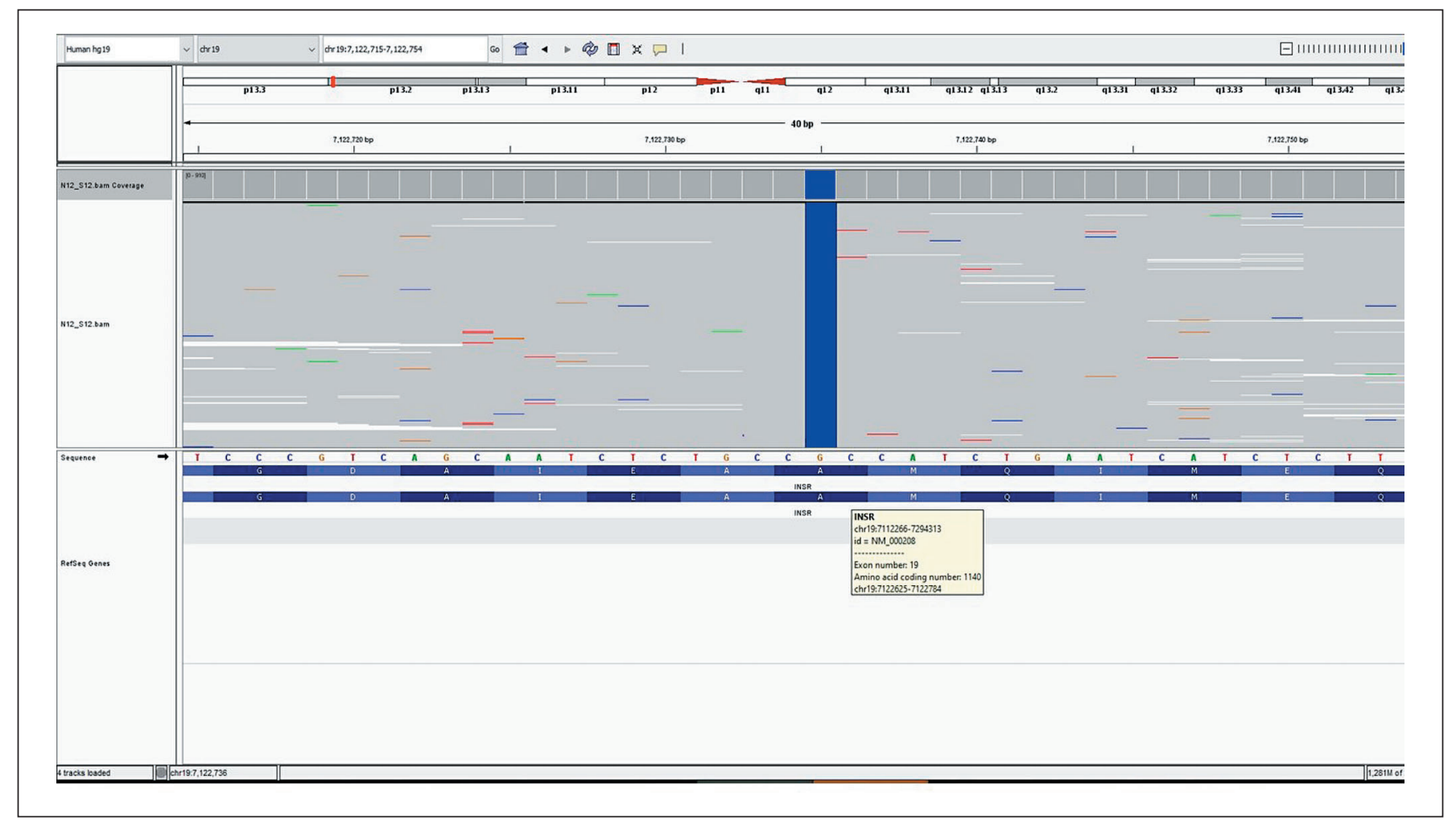

Fig. 3. Analysis of the novel homozygous variant (c.3419C>G) in exon 19 in INSR.

vealed normal size and morphology of the liver and spleen, but enlarged kidneys (right: $52 \mathrm{~mm}$, left: $55 \mathrm{~mm}$ ) with increased echogenity in parenchyma and pyramidal system. Despite increased parenchymal echogenicity, renal functions, serum and urinary calcium levels were within normal limits. Additionally, ovaries were markedly enlarged and had multiple cysts (right ovary $68 \times 44 \mathrm{~mm}$, left ovary $37 \times 23 \mathrm{~mm}$; Fig. 1d). Echocardiographic examination showed no cardiomyopathy.

In our case, severe growth retardation was present. At followup, liver cholestasis progressed and hepatosplenomegaly and ascites developed. At the last visit, she was 20 months old, her length and weight were $66 \mathrm{~cm}(-5.1 \mathrm{SD})$ and $5.8 \mathrm{~kg}(-4.8 \mathrm{SD})$, and she had severe abdominal distension due to hepatosplenomegaly and ascites. During follow-up, hyperglycemia exceeding $200 \mathrm{mg} / \mathrm{dL}$ was rarely observed. The main problem was fasting hypoglycemia which was attempted to be solved by continuous enteral feeding.

\section{Case 2}

An 8-year-old girl was referred to our clinic with severe acanthosis nigricans. Her parents are first-degree cousins. Her anthropometric measurements were within normal limits, height was $-0.57 \mathrm{SD}$ and her BMI was $0.02 \mathrm{SD}$. Physical examination revealed severe acanthosis nigricans on the neck, axillae and pubic area, hyperkeratosis, and diffuse hypertrichosis. Hyperkeratosis was evident especially in the areas of acanthosis nigricans (Fig. 4). General examination was otherwise normal. Laboratory investigations revealed an elevated fasting and 2-h postprandial insulin levels, which were 280 and $861 \mu \mathrm{IU} / \mathrm{mL}$, respectively, but concurrent glu- cose levels were normal ( 88 and $120 \mathrm{mg} / \mathrm{dL}$ ). The results of all other laboratory tests were within normal range. Continuous glucose monitorization showed fasting hypoglycemia and postprandial hyperglycemia. Severe acanthosis nigricans, normal BMI, and extremely high serum insulin levels suggested RMS. Genetic analysis revealed the previously reported homozygous NM_000208.3, c. $3529+5 \mathrm{G}>\mathrm{A}(\mathrm{IVS} 19+5 \mathrm{G}>\mathrm{A})$ variant in the INSR gene. This is a splice site variant, and in silico evaluations done by MutationTaster, Varsome, and Human splicing finder 3.1 predicts this variant as a pathogenic variant. Since the patient's clinical picture was clear and the same variant was also previously reported in another patient with RMS from our country [Tuhan et al., 2017], this variant was predicted to be pathogenic. The parents did not accept further genetic analyses.

At follow-up, high blood glucose levels were determined; thus, metformin (750 mg/day) treatment was initiated. At follow-up 1 year later, $\mathrm{HbA} 1 \mathrm{c}$ levels ranged between 6.2 and $7.3 \%$; the metformin dosage was increased steadily up to $1,500 \mathrm{mg} /$ day. Pedigrees of cases 1 and 2 are shown in Figures 5 and 6, respectively.

\section{Methods}

Genomic DNA was extracted from peripheral blood samples of the patients according to standard procedures. Genetic analyses were performed by next-generation sequencing (Miseq, Illumina, San Diego, CA, USA) following the manufacturer's instructions. 
Fig. 4. Clinical features of the patient with Rabson-Mendenhall syndrome showing acanthosis nigricans, hyperkeratosis, and hypertricosis.
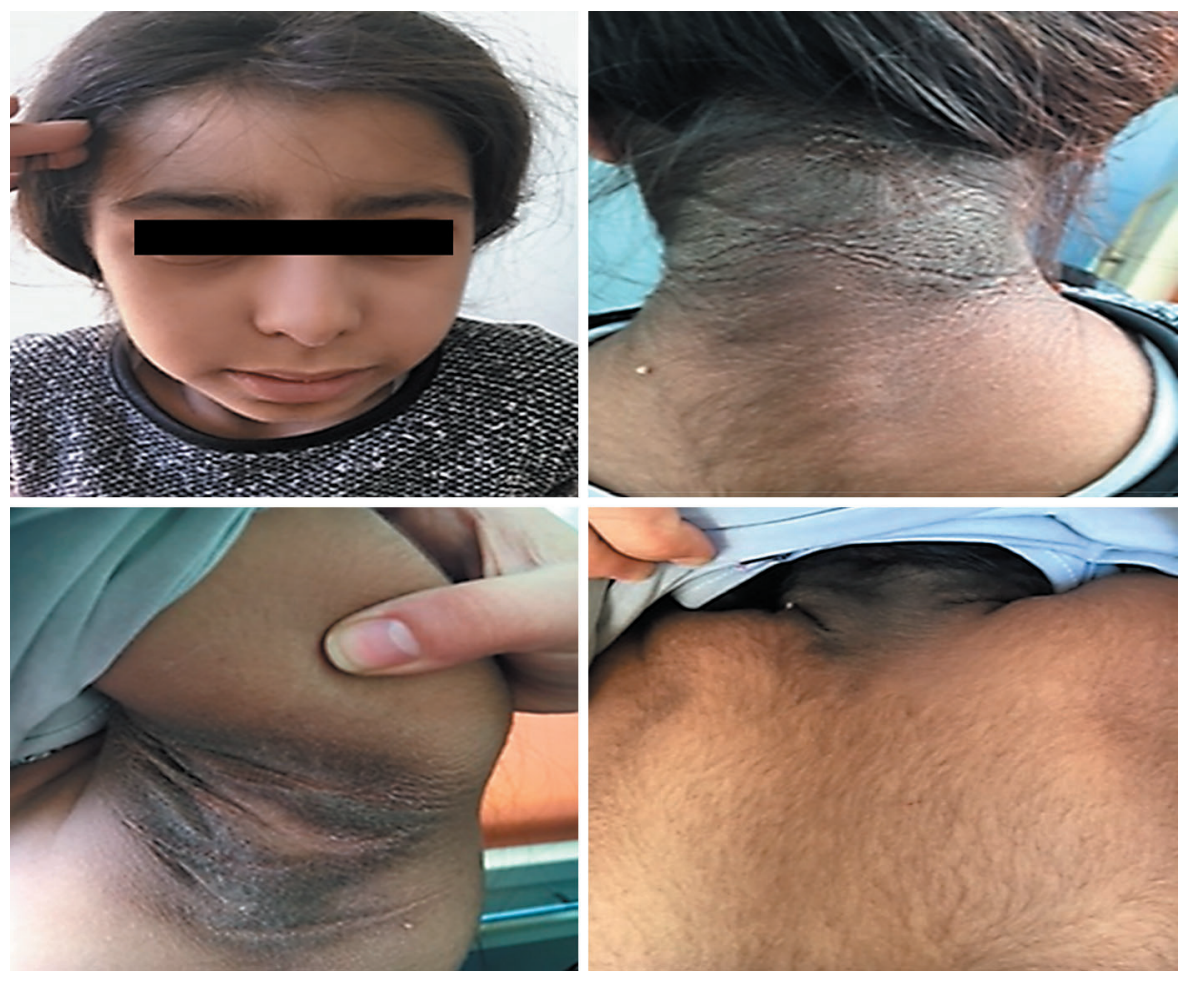

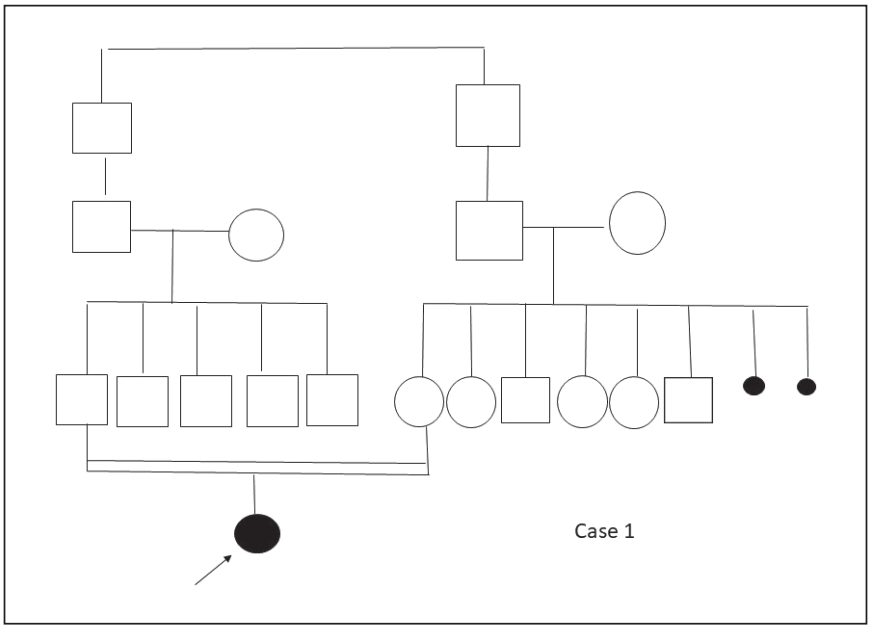

Fig. 5. Pedigree of case 1.

\section{Discussion}

DS is the most severe form of insulin resistance syndromes. The diagnosis depends on the typical dysmorphic features and is supported by exaggerated hyperinsulinemia and genetic analysis [Semple et al., 2011]. The phenotype of the first case was similar to those of previously reported infants with DS. The presence of severe

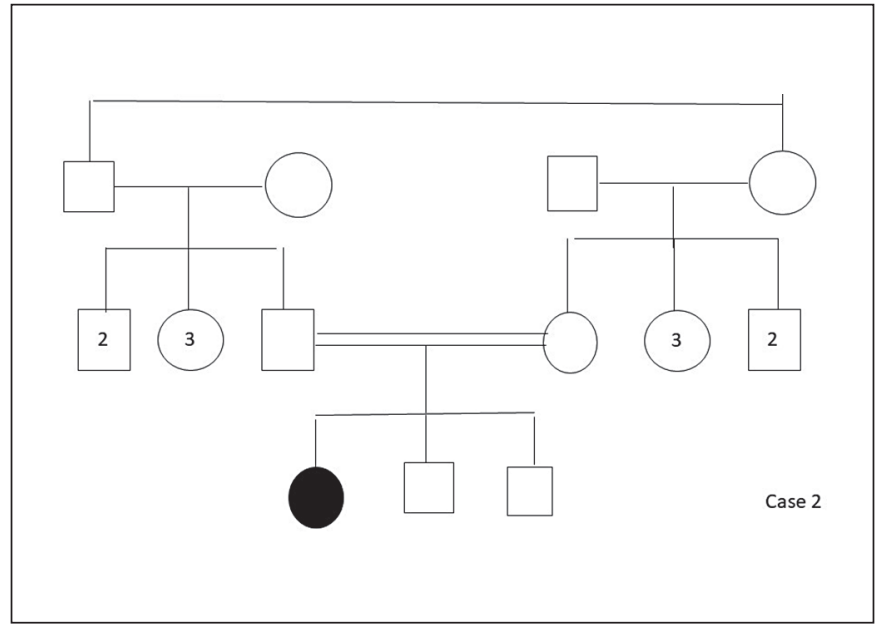

Fig. 6. Pedigree of case 2.

hyperinsulinism concurrently with hyper/hypoglycemia attacks and typical dysmorphic features suggested DS which was confirmed by genetic analysis. As expected, growth retardation in our case was severe. In patients with DS, intracellular glucose uptake is disrupted; thus, insulin-dependent adipose-muscle tissues are lost which present as atrophy. Moreover, it has been postulated that INSR-related IGF-1 and growth hormone disorders may 
be responsible for the growth retardation [Semple et al., 2010].

In our first case, cholestatic liver disease was present. Cholestasis has previously been associated with DS [Grasso et al., 2013; Odeh et al., 2015]. Hemosiderosis, cholestasis, increased fibrous tissue, and paucity of bile ducts in the portal areas were observed in postmortem examination [Gürgey et al., 1997]. Medullary sponge disease, nephrocalcinosis and renal tubular disorders are reported renal abnormalities in DS [Harris et al., 2007; Hovnik et al., 2013; Simpkin et al., 2014]. In our case, despite increase in parenchymal echogenicity, renal functions and urinary calcium excretion were normal. Cystic enlargement of the ovaries was also present in our case as a component of the syndrome, as reported previously [Unal et al., 2009; Drohobyczer et al., 2010; Azzabi et al., 2016; Kirel et al., 2017]. The exact mechanism of cystic ovarian enlargement is not known. However, it is known that high doses of insulin and IGF-1 can activate each other's receptors [Dimitriadis et al., 1992] and it is thought that heterologous activation of IGF-1 receptors could play a role in development of this situation [Geffner et al., 1987].

The second case was a mild form of RMS, presenting with severe acanthosis nigricans, hyperkeratosis and diffuse hypertrichosis, together with marked hyperinsulinemia, fasting hypoglycemia, and postprandial hyperglycemia, RMS was suggested. The diagnosis was confirmed by genetic analysis. However, other clinical findings, such as growth retardation, clitoromegaly, dysmorphic facial appearance and dental abnormalities observed in RMS were not present in our case.

Variants in the a-subunit of INSR affect the insulinbinding capacity of the receptor, whereas variants in the $\beta$-subunit affect autophosphorylation and downstream signaling transduction. It is known that variants in the $\alpha$-subunit are associated with a more severe phenotype when compared to variants in the $\beta$-subunit [Ardon et al., 2014]. The first case had 2 novel homozygous variants in INSR, c.3122del A and c.3419C $>$ G. In the second case, a homozygous variant, c. $3529+5 \mathrm{G}>\mathrm{A}$ (IVS19+5G>A), was found. Both cases had variants in the $\beta$-subunit. However, in the first case, there were 2 disease-causing variants, one of which was a frameshift variant suggesting an explanation for the more severe clinical picture.

Patients with both DS and RMS initially have fasting hypoglycemia and postprandial hyperglycemia but eventually develop constant hyperglycemia which can be followed by diabetic ketoacidosis and death [Semple et al., 2010]. Today, treatment options are limited for these syndromes. In some studies, it was shown that recombinant human insulin growth factor-1 therapy reduces glucose and insulin levels, and improves glycemic control [Nakae et al., 1998; Regan et al., 2010]. However, these were short-term studies. In the first case, the main problem was hypoglycemia, and hyperglycemia exceeding $200 \mathrm{mg} / \mathrm{dL}$ was rarely observed. This is the reason we did not choose recombinant IGF-1 for treatment. In the second case, $\mathrm{HbA} 1 \mathrm{c}$ levels varied between 6.2 and $7.3 \%$. Fasting hypoglycemia and postprandial hyperglycemia exceeding $200 \mathrm{mg} / \mathrm{dl}$ were present, but constant hyperglycemia and ketosis did not develop at follow-up. Thus, the patient is only on metformin treatment at present.

So far, there is no definitive treatment for severe insulin resistance syndromes. Therefore, it is very important to perform preimplantation genetic diagnosis and provide genetic counseling to families with a risk of having an affected child with these syndromes. As a consequence, these families could have healthy children.

\section{Acknowledgment}

We thank the patients and their families for agreeing to participate in the study.

\section{Statement of Ethics}

Parents of the affected patients gave their written informed consent. The authors have no ethical conflicts to disclose.

\section{Disclosure Statement}

The authors declare that they have no conflicts of interest.

References
Ardon O, Procter M, Tvrdik T, Longo N, Mao R:
fects and detection of two novels in INSR
gene. Mol Genet Metab Rep 1:71-84 (2014).
Azzabi O, Jilani H, Rejeb I, Siala N, Elaribi Y, et al:
Arg924X homozygous mutation in insulin re-
ceptor gene in a Tunisian patient with Dono-
hue syndrome. J Pediatr Endocrinol Metab
$29: 753-756$ (2016).
Dimitriadis G, Parry-Billings M, Bevan S, Dunger
D, Piva T, et al: Effects of insulin-like growth
factor I on the rates of glucose transport and
utilization in rat skeletal muscle in vitro. Bio-
chem J 285:269-274 (1992).
Donohue WL, Uchida I: Leprechaunism: a euphe-
mism for a rare familial disorder. J Pediatr 45:
$505-519$ (1954).


Drohobyczer D, Bellah R: Polycystic ovaries in leprechaunism. Pediatr Radiol 40:371 (2010).

-Ebina Y, Ellis L, Jarnagin K, Edery M, Graf L, et al: The human insulin receptor cDNA: the structural basis for hormone-activated transmembrane signaling. Cell 40:747-758 (1985).

- Geffner ME, Kaplan SA, Bersch N, Lippe BM, Smith WG, et al: Leprechaunism: in vitro insulin action despite genetic insulin resistance. Pediatr Res 22:286-291(1987)

-Grasso V, Colombo C, Favalli V, Galderisi A, Rabbone I, et al: Six cases with severe insulin resistance (SIR) associated with mutations of insulin receptor: is a Bartter-like syndrome a feature of congenital SIR? Acta Diabetol 50: 951-957 (2013).

-Gürgey A, Gögüs S, Saatci U, Bilgintuian N, Yordam N, et al: Leprechaunism in two Turkish patients. Turk J Pediatr 39:387-393 (1997).

-Harris AM, Hall B, Kriss VM, Fowlkes JL, Kiessling SG: Rabson-Mendenhall syndrome: medullary sponge kidney, a new component. Pediatr Nephrol 22:2141-2144 (2007).

- Hovnik T, Bratanič N, Trebušak Podkrajšek K, Kovač J, Paro D, et al: Severe progressive obstructive cardiomyopathy and renal tubular dysfunction in Donohue syndrome with decreased insulin receptor autophosphorylation due to a novel INSR mutation. Eur J Pediatr 172:1125-1129 (2013).
- Kirel B, Bozdağ Ö, Köşger P, Aydoğdu SD, Alıncak E, Tekin N: A case of Donohue syndrome "Leprechaunism" with a novel mutation in the insulin receptor gene. Turk Pediatri Ars 52:226-230 (2017).

Longo N, Langley SD, Griffin LD, Elsas LJ: Mutations in the insulin receptor and their effect on glucose transport. Trans Assoc Am Physicians 105:204-213 (1992).

Longo N, Wang Y, Pasquali M: Progressive decline in insulin levels in Rabson-Mendenhall syndrome. J Clin Endocrinol Metab 84:26232629 (1999).

Nakae J, Kato M, Murashita M, Shinohara N, Tajima T, Fujieda K: Long-term effect of recombinant human insulin-like growth factor I on metabolic and growth control in a patient with leprechaunism. J Clin Endocrinol Metab 83:542-549 (1998).

Odeh R, Alassaf A, Al-Qudah AA: Donohue syndrome a new case with a new complication. J Pediatr Endocrinol Metab 28:951-954 (2015).

- Rabson S, Mendenhall E: Familial hypertrophy of pineal body, hyperplasia of adrenal cortex and diabetes mellitus; report of 3 cases. Am J Clin Pathol 26:283-290 (1956).
Regan FM, Williams RM, McDonald A, Umpledy AM, Acerini CL, et al: Treatment with recombinant human insulin like growth factor(rhIGF)-I/rhIGF binding protein-3 complex improves metabolic control in subjects with severe insulin resistance. J Clin Endocrinol Metab 95:2113-2122 (2010).

Semple RK, Williams RM, Dunger DB: What is the best management strategy for patients with severe insulin resistance? Clin Endocrinol 73:286-290 (2010).

- Semple RK, Savage DB, Cochran EK, Gorden P, O'Rahilly S: Genetic syndromes of severe insulin resistance. Endocr Rev 32:498-514 (2011).

-Simpkin A, Cochran E, Cameron F, Dattani M, de Bock M, et al: Insulin receptor and the kidney: nephrocalcinosis in patients with recessive INSR mutations. Nephron Physiol 128:55-61 (2014).

Tuhan H, Ceylaner S, Nalbantoğlu O, Acar S, Abac1 A, et al: A mutation in INSR in a child presenting with severe acanthosis nigricans. J Clin Res Pediatr Endocrinol 9:371-374 (2017).

-Unal S, Aycan Z, Halsall DJ, Kibar AE, Eker S, Ozaydin E: Donohue syndrome in a neonate with homozygous deletion of exon 3 of the insulin receptor gene. J Pediatr Endocr Met 22: 669-674 (2009). 